\title{
The effect of the thermal inertia on the thermal transfer in building wall
}

\author{
Lahcene Bellahcene ${ }^{1, *}$, Ali Cheknane $^{2}$, SMA. Bekkouche ${ }^{3}$, and Djemal Sahel ${ }^{4}$ \\ ${ }^{1}$ Mechanical laboratory, Department of Mechanical Engineering, Amar Thelidji University of \\ Laghouat BP $37 \mathrm{G}$ road of Ghardaïa, Algeria \\ ${ }^{2}$ Laboratory for the Study and Development of Dielectric Materials and Semiconductor, Amar Telidji \\ University of Laghouat BP $37 \mathrm{G}$ road of Ghardaïa, Algeria \\ ${ }^{3}$ Applied Research Unit on Renewable Energies, URAER, B.P. 88, ZI, Gart. Taam, Ghardaïa, Algeria \\ ${ }^{4}$ Gas Fuels and Environment Laboratory, Mechanical Engineering Faculty, University of Sciences \\ and the Technology -Oran, USTO-MB, BP 1505, El-M'Naouer, Oran 31000, Algeria
}

\begin{abstract}
In a hot and dry climate, the design and construction of buildings involve the adoption of combination between shape of building envelope and construction materials. The objective of this work is to study the thermal behavior of a multilayer wall submitted to varying climatic conditions. We have proposed four configurations of an element of an outer wall. A numerical simulation was used to understand the phenomenon of thermal inertia, especially its influence on the resulting temperatures. The study is based on the modeling of heat transfer in a $2 \mathrm{D}$ unsteady-state using a computational fluid dynamics (CFD) code. The comparison of numerical results was affected with an available experimental data and shows a satisfactory agreement. In addition, this work highlights the importance of the study of the thermal inertia of the wall in order to ensure a comfortable indoor climate of building located in hot and dry climate.
\end{abstract}

\section{Introduction}

In desert regions, unsuitable adaptation of the building design and its indoor environment can result in a greater need for active climatisation and, thus, increased the using energy. The design and construction of a building involve the adoption of three elements: typology, shape and technology. The shape of a building is a crucial factor to achieving the relationship between cost and comfort [1]. Some properties that are related to building shape and which influence heating and cooling requirements are: compactness index, the height of walls, climate, and the characteristics of the building envelope. The previous characteristics are important variables of the energy requirements for maintaining the building at a comfortable temperature [2]. The thermal performance of the building envelope can make a significant contribution to decrease the needed energy. So, it is important to insulating the envelope of the building [3]. The determination of the temperature of the walls that constitute the building envelope may consider as an essential

${ }^{*}$ Corresponding author: belahcene.ste@gmail.com 
part of an efficient building design. The thermal performance of an opaque wall depends on how well its materials transfer the heat flux through it, and the weather conditions [4]. The building envelopes propose an essential element between occupied building spaces and weather conditions. Thermal insulation in the walls is often designed for static performance based on its thermal resistance [5]. Karlsson et al. [6] show the energy used for maintaining of comfortable indoor temperatures depends on the thermal storage capacity of walls in the contact with the indoor air. They studied the effects of increasing of the thermal storage capacity of building materials. Thermal inertia of buildings can help to reduce such consumption, improve comfort, and even replace HVAC (Heating, Ventilation and AirConditioning) systems. This thermal inertia is usually associated to heavy wall construction, but in fact, there is other parameters that can affect a significantly this property [7]. Many researchers reported the heat transfer in multilayer walls. Tamene [8] studied numerically heat transfer through an exterior multilayer wall of a house subjected to real conditions. Moreover, Ibrahim et al. [9] examined the energy behaviour of the buildings' multilayer exterior wall structures. The aim of the present work was to find the best wall structure and the number and position of insulation layers within exterior walls for continuous heating, intermittent heating, and no heating operation modes for some commonly used construction materials.

Generally, the thermal inertia is a character used for modeling heat transfers and it is a property of mass material related to thermal conductivity and capacity volumetric heat. In the envelope of building thermal transfer aspect, thermal inertia is responsible of the reduction of inside air temperature peaks and for the delay between the accumulation of energy and its respective release. Also, it depends on two factors namely time lag and decrement factor, they are influenced by thermo-physical properties of the material, thickness and wall position's. In the heat storage capacities the essential characteristics are time lag and decrement factor [10]. Numerous works have been performed in this field. Kontoleon et al. [11] analyzed in detail the impact of the concrete density and conductivity variations on decrement factor $(f)$ and time lag $(\varphi)$ on six insulated wall assemblies. Mavromatidis et al. [12] developed a numerical model of a multilayer wall. They used the time $\log$ and decrement factor for a building wall including different configurations of multilayer thermal insulation.

In this work, the study was devoted to the numerical simulation by using a computational fluid dynamics (CFD) code; this code is used to simulate the temperature in a 2D unsteady-state of a multilayer wall. We have proposed four configurations of an element of an outer wall. The main purpose of this study is to characterize the thermal inertia of building wall in hot and dry climate.

\section{Mathematical models}

In this section, a mathematical model is proposed to assess the energy performance of a multilayer wall. This model applies only to heat exchanges. A wall of four layers; two layers of cement mortar, a heavy stone layer and a layer of plaster. The wall is subjected to varying climatic conditions, where $(\mathrm{L})$ and $(\mathrm{H})$ represent the length and height, respectively. The direction of the heat transfer is in the $\mathrm{x}$ direction. So, $\mathrm{x}=0$ is for outer surface and $\mathrm{x}=\mathrm{L}$ for inner surface. The values of inner and outer convection heat transfer coefficients are $9\left(\mathrm{~W} / \mathrm{m}^{2} \mathrm{~K}\right)$ and $17\left(\mathrm{~W} / \mathrm{m}^{2} \mathrm{~K}\right)$ respectively in period of summer season in Ghardaïa region. The proposed mathematical model contains certain assumptions that are important considerations that have already been tested and do not have an influence on the creation and use of this model. It is assumed as: Heat transfer through the walls is assumed unidirectional and perpendicular to these walls. 

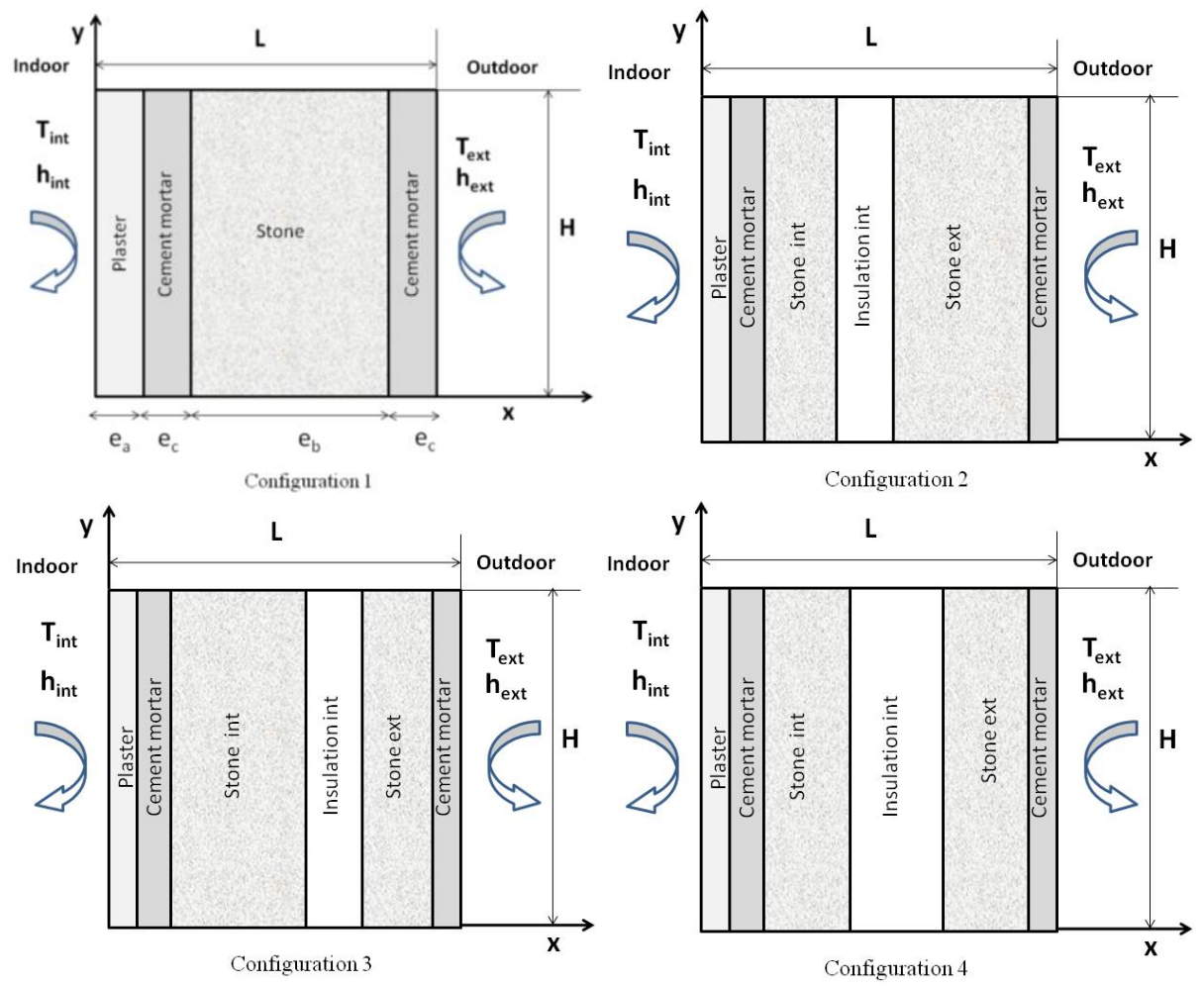

Fig. 1. Multilayer wall configurations studied with boundary conditions.

The distribution of the temperature on the outer and inner surfaces of the wall is uniform. Consider a multilayer wall thickness (L) without internal source and in thermal equilibrium at the initial time at temperature $\mathrm{T}_{0}$. This wall subject to the boundary conditions of Dirichlet: $T(0, t)$ and $T(L, t)$ is shown schematically in fig.1. It is assumed that the thermophysical properties of the wall are constants. The materials considered are those generally used in Algeria in the construction of buildings, their thermal physical properties are shown in Table 1.

Table 1. The thermal physical properties using in the simulation.

\begin{tabular}{|c|c|c|c|}
\hline & $\begin{array}{c}\boldsymbol{\lambda} \\
{[\mathbf{W} / \mathbf{m} . \mathbf{K}]}\end{array}$ & $\begin{array}{c}\mathbf{\rho} \\
{\left[\mathbf{k g} / \mathbf{m}^{3}\right]}\end{array}$ & $\begin{array}{c}\mathbf{C p} \\
{[\mathbf{J} / \mathbf{k g . K}]}\end{array}$ \\
\hline Mortar & 1.15 & 1900 & 864 \\
\hline stone & 2.8 & 2600 & 702 \\
\hline plaster & 0.4 & 1440 & 840 \\
\hline
\end{tabular}

\subsection{Mathematical formulation}

All papers should be concise regardless of length. Long quotations should be avoided by referring to sources. Illustrations and tables, where they help clarify the meaning or are 
necessary to demonstrate results properly, are desirable, but they should be kept to a practicable minimum, and included on individual pages at the end of the manuscript.

Given these assumptions, the heat balance equations are unsteady two-dimensional conduction equation in solid material:

$$
\rho c \frac{\partial T}{\partial t}=\frac{\partial}{\partial x}\left(\lambda \frac{\partial T}{\partial x}\right)+\frac{\partial}{\partial y}\left(\lambda \frac{\partial T}{\partial y}\right)
$$

Boundary conditions:

$$
\begin{aligned}
& -\lambda_{a} \frac{\partial T}{\partial x}=h_{e x t}\left(T_{f e}-T_{e w}\right) ; \quad x=0 \\
& -\lambda_{c} \frac{\partial T}{\partial x}=h_{\mathrm{int}}\left(T_{i w}-T_{f i}\right), \quad x=L \\
& \frac{\partial T}{\partial y}=0, \text { at } y=0, \frac{\partial T}{\partial y}=0, y=H
\end{aligned}
$$

Initial conditions:

$$
\begin{aligned}
& T_{w}=T_{0}, t=0, \text { for } 0 \leq x \leq L, \\
& T_{\text {ext }}(t)=T_{1}+\Delta T_{1} \sin (w t) \\
& T_{\text {int }}(t)=T_{2}+\Delta T_{2} \sin (w t)
\end{aligned}
$$

Where: $\mathrm{w}=2 \pi / \tau, \tau=1440 \min , T_{1}=38.5^{\circ} \mathrm{C}, T_{2}=38^{\circ} \mathrm{C}, \Delta T_{I}=8^{\circ} \mathrm{C}, \Delta T_{2}=8^{\circ} \mathrm{C}$.

\section{Results and discussion}

Analysis by the experimental study of the thermal inertia in an exterior wall of a building on measured the temperatures each tin minutes $(\Delta \mathrm{t}=10 \mathrm{~min})$. It measures the temperatures on the left and right side of the wall. Knowledge of the evolution of temperatures makes it easier Knowledge of the evolution of temperatures allows bettering understanding the phenomena of thermal inertia, storage and retrieval of heat in the wall. This section discusses thermal inertia effect on measured indoor air temperatures in a building in an arid region of Algeria, the measurements make at the Unit for Applied Renewable Energy Ghardaïa.

Fig. 2a shows the validation of the simulation model by comparing it with the measured data during a very hot period. The results of numerical simulation effected with two days in the period studied by considering the climate of the city of Ghardaïa (20-21 July 2008). By analyzing the variation of temperature with time, the results shows in Fig. $2 b$ that the fluctuation of the temperature wave in configuration (1) is smaller than the temperature wave in the others configurations environ $1^{\circ} \mathrm{C}$. 

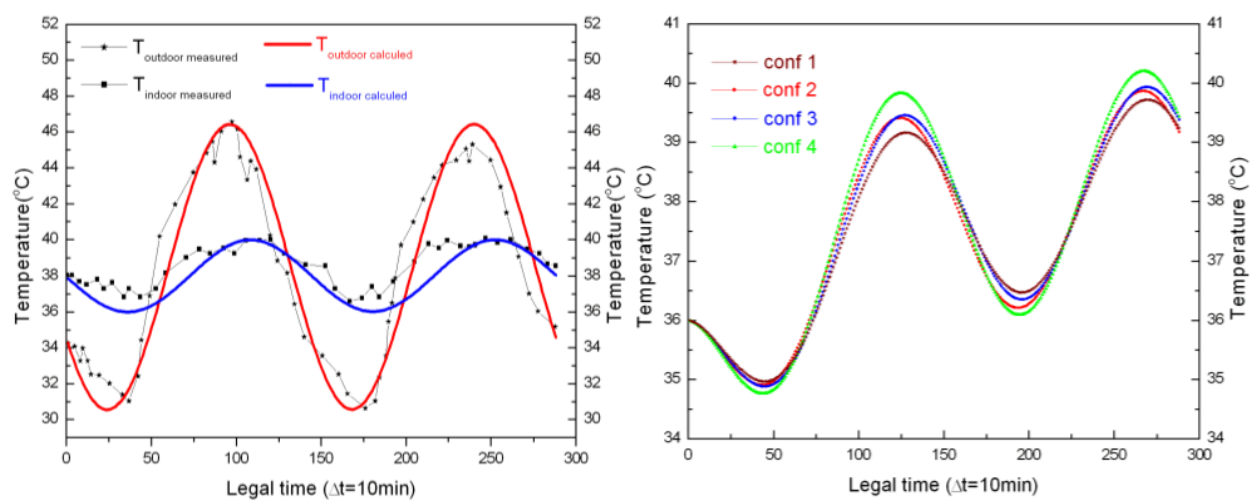

Fig. 2. (a): Validation of numerical model with experimental results and (b): temperatures resultant of wall configurations.

For the day of July 20 , the calculated minimum temperature of the outer surface of the wall is $31.10^{\circ} \mathrm{C}$; the minimum measured value is $31.07^{\circ} \mathrm{C}$. The calculated and measured maximum values are respectively $45.70^{\circ} \mathrm{C}$ and $39.90^{\circ} \mathrm{C}$. Furthermore, the inner surface temperature of the wall including the minimum value is calculated to $36.08^{\circ} \mathrm{C}$, while its measured minimum value is $36.90^{\circ} \mathrm{C}$. The calculated maximum value is reached $39.90^{\circ} \mathrm{C}$ and the maximum value measured is $40.10^{\circ} \mathrm{C}$. All measured data was found in good agreement with the simulated data, we can see a very good consistency between the results obtained by the two methods.

\subsection{Time lag $(\varphi)$ and decrement factor $(f)$}

The time lag and decrement factor are assumed as important parameter to determine the thermal inertia of different building materials, when the thermal behavior of a wall is studied of unsteady state boundary conditions. The time it takes for the temperatures wave imposed on the left side to propagate from the right side named as "time lag" $(\varphi)$ and the decreasing ratio of its amplitude during is named as "decrement factor" $(f)$ [12].

The time lag $(\varphi)$ and decrement factor $(f)$ are defined by the following equations [14].

$$
\begin{gathered}
\varphi_{\text {min }}=t_{T i, \text { min }}-t_{T o, \text { min }} \\
\varphi_{\text {max }}=t_{T i, \text { max }}-t_{T o, \text { max }} \\
f=\frac{T_{i, \text { max }}-T_{i, \text { min }}}{T_{o, \text { max }}-T_{o, \text { min }}}
\end{gathered}
$$

$t_{T o, \min }, t_{T i, \min }, t_{T o, \max }$ and $t_{T i, \max }$ are the times when the temperatures are imposed on its left and right side of the wall surfaces reach the minimum and maximum values.

$T_{o, \min }, T_{i, \min }, T_{o, \max }$ and $T_{i, \max }$ are respectively the minimum and maximum temperatures imposed on left and right side of the wall.

Fig. 3 shows the time lag $(\varphi)$ and decrement factor $(f)$ calculate of walls with thermal insulation. By analyzing the change in temperature as a function of time, we notice a thick heavy stone wall is not isolated in these conditions. But, it will slow down by its inertia, the input of heat flux. In principle, the indoor ambient must remain cool in summer thanks to their Stone walls with high heat storage capacity. These thick walls have a strong time log to bring the freshness the night in the wall and the return day. For this, the stone will 
become the ideal material: dense, capable of storing and conductive to promote the storage provided there is fresh night. Indeed, that's the problem in these arid regions: in summer, the outdoor ambient temperatures remain high almost all the time even during the night. So, the thermal inertia consists of an accumulation of heat in the envelope for an interior return radiation. The complexity of this phenomenon is that the flow of heat through the shell successively increases the temperature of materials which allows increasing at the same time the air temperature habitat. The results support the conclusion that the mathematical models are good enough to predict the effective thermal behavior of the building under real weather conditions.
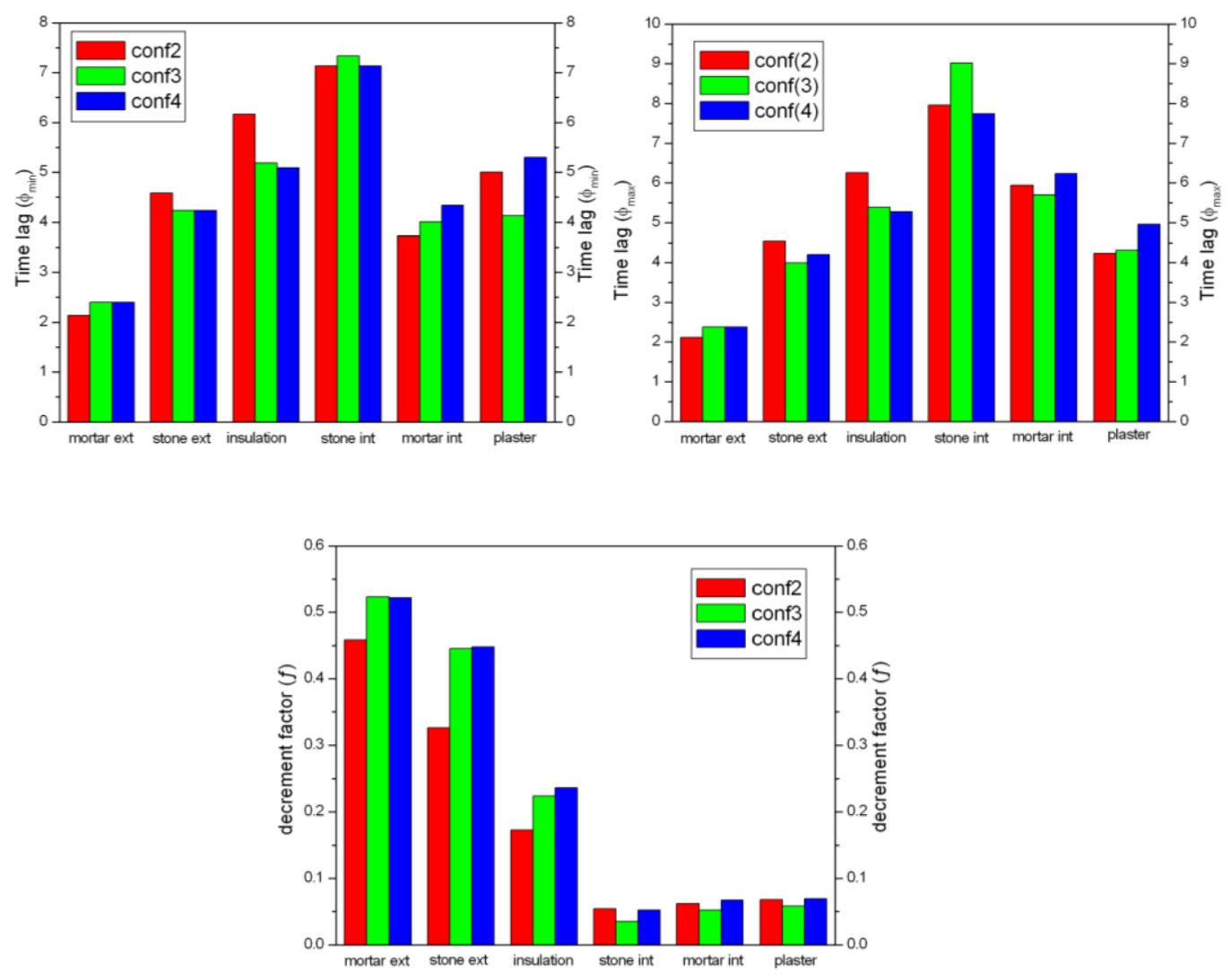

Fig. 3. (a): The time lag $\left(\varphi_{\min }\right),(b)$ : The time lag $\left(\varphi_{\max }\right)$ and $(\mathrm{c})$ : decrement factor $(f)$.

\section{Conclusions}

A numerical simulation is used to analyze and descript the phenomenon of thermal inertia in the walls. We wanted to show through this study that the high inertia walls are the main passive means to improve the thermal comfort in the hot and dry climate zone.

The results obtained are experimentally validated, and mainly showed that the wall deadens and delays the variations in the temperature between inside and outside of the building. The choice of construction materials plays an essential role in the comfort level of the buildings and reducing the energy consumption. Indeed, the inertia of the wall decreases and delays the effect of external conditions and is particularly suited to the hot and dry climate. This is clear from the results. 


\section{References}

1. S.M.A. Bekkouche, T. Benouazb, M. Hamdania, M.K. Cheriera, M.R. Yaichec, N. Benamranea, J. Buil. Eng. 1, 42 (2015)

2. S.M.A. Bekkouche, T. Benouazb, M.K. Cheriera, M.R. Hamdani, M.R. Yaichec, N. Benamranea, J. Ene. Buil. 66, 678 (2013)

3. S.M.A. Bekkouche, T. Benouazb, M.K. Cheriera, M. Hamdani, M.R. Yaichec, R. Khanniche, J. Therm. Sci. 17, 349 (2013)

4. K.J. Kontoleon, Th.G. Theodosiou, K.G. Tsikaloudaki, J. App. Ene. 112, 325 (2013)

5. D.E.M. Bond, W.W. Clark, M. Kimber, J. App. Ene. 112, 235 (2013)

6. J. Karlsson, L. Wadsö, M. Öberg, J. Ene. Buil. 60, 146 (2013)

7. J.A. Orosa, A.C. Oliveira, J. Renew. Ene. 37, 89 (2012)

8. Y. Tamene, S. Abboudi, C. Bougriou, Revue des éne. Ren. 12, 117 (2009)

9. M. Ibrahim, P.H. Biwole, E. Wurtz, P. Achard, Buil. Env. 81,112 (2014)

10. S.C. Ng, K.S. Low, N.H. Tioh, Ene. Buil. 43, 2956 (2011)

11. K.J. Kontoleon, T.G. Theodosiou, K.G Tsikaloudaki, App. Ene. 112, 325 (2013)

12. L.E. Mavromatidis, M. EL Mankibi, P. Michel, M. Santamouris, App. Ene. 92, 480 (2012)

13. C. Tonelli, M. Grimaudo, Buil. 83, 89 (2014)

14. H. Asan, Y.S. Sancaktar, Ene. Buil. 28, 159 (1998) 